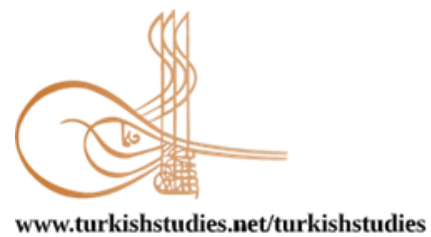

Turkish Studies

\title{
Covid-19'lu Hastalara Tedavi ve Bakım Veren Sağlık Çalışanlarının Görüşlerinin Belirlenmesi
}

\author{
Determining the Views of Healthcare Professionals Providing Treatment and Care to \\ Patients with Covid-19
}

\author{
Sıddıka Ersoy * - Şükran Özkahraman Koç** - İsmail Hakkı Ersoy***
}

\begin{abstract}
Healthcare professionals have a major role to play in controlling pandemic such as Covid-19 that have spread all over the world. In this study, we aimed to determine the views of healthcare professionals providing treatment and care to Covid-19 patients. In addition, it was decided by the Süleyman Demirel University Faculty of Medicine Clinical Research Ethics Committee, with the decision dated 174 and numbered 2020.07.23, it was decided to comply with ethical scientific standards. The descriptive and crosssectional study was carried out between April - May 2020 with a total of 407 healthcare workers, $42.0 \%$ were nurses, $30.7 \%$ doctors and $27.3 \%$ other health workers. The universe of the study consists of 578 healthcare workers. The Healthcare professionals' views were evaluated with a questionnaire consisting of Personal Information Form, Depression Anxiety Stress Scale short form and questions determining healthcare professionals' thoughts before and after pandemics. It was found that $81.1 \%$ of the healthcare professionals had friends before the Covid-19 pandemic and 73.5\% did not receive psychological support. There is a statistical significance between the healthcare professionals participating in the study and their psychological support status before the Covid-19 pandemic, and the scale total score and sub-dimensions $(\mathrm{p}=0.000)$. Some of the participants stated that they found themselves socially active $(\mathrm{n}=281)$, physical $(n=249)$ and psychological $(n=200)$ before the Covid-19 pandemic, but this situation was adversely affected after the Covid-19 pandemic. It was observed that the majority of healthcare professionals did not have an expected negative attitude towards pandemic and cases in the early period. Providing psychological support trainings to all healthcare professionals in the period after the Covid-19 pandemic can yield important results.
\end{abstract}

* Dr. Öğr. Üyesi, Süleyman Demirel Üniversitesi, Sağllk Bilimleri Fakültesi, Hemşirelik Bölümü

Asst. Prof. Dr., Süleyman Demirel University, Faculty of Health Science, Department of Nursing ORCID 0000-0001-8094-8042

siddikaersoy@gmail.com

*** Prof. Dr., Süleyman Demirel Üniversitesi, Sağlık Bilimleri Fakültesi, Ebelik Bölümü

Professor, Süleyman Demirel University, Faculty of Health Sciences, Department of Midwifery

ORCID 0000-0001-7286-6477

sukran.ozkahraman@gmail.com

${ }^{* * * *}$ Doç.Dr., Isparta Şehir Hastanesi, Endokrinoloji ve Metabolizma Hastalıkları Bölümü

Associate Professor, Isparta City Hospital, Department of Endocrinology and Metabolism

ORCID 0000-0002-3785-6393

hakkiersoy@gmail.com

Cite as/ Atıf: Ersoy, S., Özkahraman Koç, Ş. \& Ersoy, İ. H. (2020). Covid-19'lu hastalara tedavi ve bakım veren sağlı çalışanlarının görüşlerinin belirlenmesi. Turkish Studies, 15(6), 1037-1049. https://dx.doi.org/10.7827/TurkishStudies.43662

Received/Geliș: 17 May/Mayıs 2020

Accepted/Kabul: 15 October/Ekim 2020

Copyright $(\mathrm{C}$ MDE, Turkey

Checked by plagiarism software

Published/Yayın: 20 October/Ekim 2020

CC BY-NC 4.0 


\section{Structured Abstract: Introduction}

The main center of Covid-19 started as Asia-China and then as a secondary center Turkey's geological showing rapid spread Covid-19 placement in Europe, starting with Asia in terms of trade by reason of being a bridge between Europe has been losing its importance since then. Countries' initial exposure to infection varied. Factors such as health policy of countries, preliminary preparations, average age of society; The course of the disease affects the process related to conditions such as the duration of pandemic control, the variety and severity of mental problems that may occur. first seen by the Ministry of Health in Turkey's case is given as March 10, 2020. Our reason for choosing the province of Isparta in the research is that the prevalence of the disease in our country in the first weeks is the highest in comparison to the population.

\section{Purpose}

In this study, we aimed to determine the views of healthcare professionals providing treatment and care to Covid-19 patients.

\section{Method}

This study conducted between April and May 2020. The universe of this study, which is descriptive and cross sectional, was composed of healthcare workers in Isparta City Hospital, where the patient hospitalization was the most frequent in the province during the pandemic and took an active role in the care process.

\section{Participants}

The universe of the study consists of 578 healthcare workers. A total of 407 health care professionals, of whom $42.00 \%$ were nurses, $30.70 \%$ doctors and $27.30 \%$ other health workers, were included in the study.

Data Collection Tools: The questionnaire used in this study consists of three parts. It the first part of the questionnaire used in the study there is an information form. This form was created by researchers. The personal information form includes questions about age, gender, educational background, profession, family structure, having children, the presence of regular groups of friends and psychological support before the pandemic. In the second part of the questionnaire, there is a short form of Depression Anxiety Stress Scale (DASS-21). The Depression Anxiety Stress Scale (DASS) developed by Lovibond and Lovibond in 1995 consists of 42 items and 3 sub-dimensions. The scale has a 4-point likert-type rating, ranging from 0 "not at all convenient to me" to 3 "completely suitable to me". While conducting studies with the scale, the idea that shorter forms of this scale can perform the same measurement in 1997; thereupon, the 21-question short form (DASS-21) created by Henry and Crawford was designed to contain 7 questions to measure the dimensions of depression, stress and anxiety. The scoring of the DASS-21 short form is the same as in the long form. Again, as in the long form, it consists of 3 sub-dimensions: Anxiety (DASS-21A), Depression (DASS-21D) and Stress (DASS-21S). The lowest score for each sub-dimension is 0 and the highest score is 21 . The validity and reliability study of the DASS-21 scale was performed in 2017 by Y1lmaz et al. and adapted to the Turkish society. Depression Anxiety Stress Scale's sub-dimensions of DASS-21A's cronbach alpha value is .80, DASS-21D's .81, DASS-21S's .75. In this study, cronbach alpha value is DASS21A's .81, DASS-21D's .82, DASS-21S's. 77.

Literature and questions before the 30-point pandemic situation that was created after considering and thoughts can be answered in Turkey as compared to the third part of the questionnaire related by researchers located.

Statistical analysis: Data, descriptive statistics in SPSS 22.0 statistical package program, t-test, Single Directional Variance Analysis was evaluated with Kruskall Wallis, Wilcoxon sign test. P value less than 0.05 was considered statistically significant.

\section{Results}

The DASS-21S subscale score shows a statistically significant relationship with the presence of a group of friends whom healthcare professionals participated in the research regularly $(\mathrm{t}=2.031 / \mathrm{p}=0.044)$. There was a statistical significance between the participants' psychological support prior to the Covid-19 pandemic and their total score and sub-dimensions $(\mathrm{p}=0.000)$. Some of the healthcare professionals 
participating in the research before and after Covid-19 pandemic opinions were received on the state of experiencing emotions and maintaining certain behaviors. For some questions, the increase in responses about emotions experienced before and after the covid-19 pandemic is remarkable. Most of the participants were nervous in the working environment, thought to resign and were resentful due to the abolition of their resignation rights during this period, they were angered due to the abolition of their right to resign, that they held themselves responsible for the increased workload of their friends when they could not come to work for any reason, They stated that they thought they lived, they experienced sleep problems, the weight of life increased and they felt in a dead end, they experienced death anxiety about themselves and their loved ones, they felt more helpless due to isolations, and were supported more by their administrators in this period.

\section{Conclusion}

When we examine the responses given to the questions of the opinions of our healthcare professionals, they responded to the fact that they love their jobs less in the early period, think more resignation and feel angry because they cannot resign, have a death anxiety about themselves and their relatives, and in parallel, their life conditions are more severe and they even think about suicide. It is interesting. It can be stated that healthcare professionals do not have high DASS-21 scale scores, and that they experience serious turmoil at the level of thought. Healthcare professionals it was found that most of them did not have an expected negative attitude towards pandemic and cases even in the early period. In addition, healthcare professionals in our study were found to experience anxiety, depression and stress disorders less than healthcare professionals in other countries and were less affected by pandemics. They stated that while experiencing these thoughts, they also experienced many internal turmoil. As a result of the socially respected love of our healthcare professionals due to the cultural structure of our society, and because the study was planned in the weeks when the first cases were seen in our country, there were no signs of intense stress, anxiety and depression. We think that psychological support programs should be organized for all healthcare professionals in order to avoid larger problems in the period after the Covid-19 pandemic

Keywords: Pandemic, Covid-19, Anxiety, Depression, Stress, Healthcare Professionals

Öz: Covid-19 gibi tüm dünyaya yayılımı olan salgınların kontrol altına alınmasında sağlık çalışanlarına büyük görevler düşmektedir. Çalışma Covid-19'lu hastalara tedavi ve bakım veren sağlık çalışanlarının görüşlerini belirlemek amacıyla yapılmıştır. Ayrıca Süleyman Demirel Üniversitesi Tıp Fakültesi Klinik Araştırmalar Etik Kurulundan, 23.07.2020 tarih ve 174 nolu karar ile etik bilimsel standartlar açısından uygunluğuna karar verilmiştir. Tanımlayıcı ve kesitsel tipte olan çalışma Nisan-Mayıs 2020 tarihleri arasında \%42.0'1 hemşire, \%30.7'si doktor ve \%27.3’ü diğer sağlık çalışanları olmak üzere toplam 407 sağlık çalışanıyla gerçekleştirilmiştir. Çalışmanın evreni 578 sağlık çalışanından oluşmaktadır. Sağlık çalışanlarının görüşleri Kişisel Bilgi Formu, Depresyon Anksiyete Stres Ölçeği kısa formu ve sağlık çalışanlarının pandemi öncesi ve sonrası düşüncelerini belirleyen sorulardan oluşan anketle değerlendirilmiştir. Sağlık çalışanlarının Covid-19 salgınından önce \%81.1'inin arkadaş gruplarının olduğu ve \%73.5'inin psikolojik destek almadığı bulunmuştur. Araştırmaya katılan sağlık çalışanlarının Covid-19 salgını öncesinde psikolojik destek alma durumları ile ölçek toplam puan ve alt boyutları arasında istatistiksel anlamlılık bulunmaktadır $(p=0.000)$. Katılımcıların bazıları Covid-19 salgını öncesi kendilerini sosyal olarak aktif buldukları ( $\mathrm{n}=281$ ), fiziksel $(n=249)$ ve psikolojik $(n=200)$ iyi hissettikleri ancak bu durumun Covid-19 salgınından sonra olumsuz olarak etkilendiğini belirtmişlerdir. Sağlık çalışanlarının çoğunluğunun erken dönemde salgına ve vakalara karşı beklenen düzeyde olumsuz bir tutum içinde olmadıkları görülmüştür. Covid-19 salgını sonrasında ki dönemde sağlık çalışanlarının tamamına psikolojik destek verilmesi önerilebilir.

Anahtar Kelimeler: Salgın, Covid-19, Anksiyete, Depresyon, Stres, Sağlık Çalışanları

\section{Giriş}

Koronavirusler (CoV), soğuk algınlığından Orta Doğu Solunum Sendromu (MERS-CoV) ve Şiddetli Akut Solunum Sendromu (SARS-CoV) gibi daha ciddi hastalıklara neden olan ve uzun zamandır bilinen büyük bir virüs ailesi olarak tanımlanmaktadır (Sağlık Bakanlığı, 2020a) Dünya Sağlık Örgütü (DSÖ) tarafindan 31 Aralık 2019'da Çin'in Hubei eyaleti Wuhan'daki yeni 
pnömonin ilk raporlarından bu yana (Zhou vd., 2020:270-273; Sağlık Bakanlığı, 2020a), Covid-19 salgını dünya çapında hızla yayılmaya devam etmektedir. DSÖ 11 Mart 2020'de, Covid-19 virüsünün dünya çapında giderek yayılması nedeniyle halk sağlığını önemli ölçüde tehdit eden önemli bu salgını küresel salgın olarak tanımlanabileceğini ilan etmiştir (https://coronavirus.jhu.edu, 2020; World Health Organization, 2020). Dünyada Nisan sonu 2020 itibariyle global olarak konfirme edilen vaka sayısı 3 milyon kişiyi, ölüm sayısı da 200.000 kişiyi aşmıştır (https://coronavirus.jhu.edu, 2020). Çin Ulusal Sağlık Komisyonu'ndan alınan verilere dayanarak sadece Çin'de 3300'den fazla sağlık çalışanının Mart ayı başına kadar enfekte olduğu belirtilmiştir (The Lancet, 2020:922).

Salgının başlangıcından itibaren yayınlarda genel olarak vurgulanan asıl nokta enfeksiyondan korunmak için alınabilecek önlemler ve koruyucu ekipmanların doğru kullanımı konuları olmuştur The Lancet, 2020:922; Ağalar ve Öztürk Engin, 2020:578-584; Rohan vd., 2020:66). Ancak sağlık çalışanlarının açıklamaları raporlandığında tek kaygılarının enfeksiyona yakalanma kaygısı olmadığı; ciddi anlamda fiziksel ve zihinsel yorgunluk yaşadıkları, triyaj kararlarının verdiği sıkıntılar nedeniyle zor durumlar yaşadıkları, üstüne hasta ve meslektaşlarını kaybetmenin acısı eklendikçe daha çok psikolojik yıpranma yaşadıkları belirtilmektedir The Lancet, 2020:922). SARS salgınından kurtulanların incelendiği bir çalışmada psikiyatrik bozukluk insidans1 \%60'a yakın bulunmuştur (Mak vd., 2009:318-326). Yine SARS salgınları döneminde yapılan çalışmalarda sağlık çalışanlarının stres, kaygı, depresyon ve genel psikolojik bozukluklarının arttı̆̆ı yönünde veriler olduğu belirtilmektedir Wu vd., 2009:302-311; Xiang vd., 2020:228-229).

Covid-19 gibi tüm dünyada yayılımı hızlı olan durumların kontrol altına alınmasında, özellikle ilk müdahaleyi yapan sağlık çalışanlarının erken dönemde olaya adaptasyonları ve başa çıkma mekanizmalarının gelişmesi kriz yönetimini etkin kılacak ana noktalardan biridir. Ayrıca unutulmaması gereken bir diğer husus salgın kontrol altına alındıktan sonraki yaşam dönemlerimiz boyunca da sağlık çalışanlarına ihtiyaç duymaya devam edeceğimiz gerçeğidir. Yapılan çalışmalarda stresle baş etme mekanizmalarının kullanımı, kriz dönemine hazırlıklı olma, sürekli eğitimler, özellikli birimlerde çalışma, sosyal desteğin iyi olması gibi birçok kriterin ruh sağlığını ve zihinsel olarak süreci yönetme becerilerini olumlu etkileyebileceği belirtilmektedir (Brooks vd., 2020:52-56). Ayrıca sağlık çalışanlarının ruhsal yönden desteklenmemesi durumlarında artan stres ve kaygı durumlarının sonucunda kaçınma davranışlarının gelişebileceği ve bu durumun ek olarak hastalıkların yönetimini de zorlaştıracağı ifade edilmektedir (Shultz vd., 2016:104). Daha önceki salgın durumlarında yapılan çalışmalar tarafından da desteklendiği üzere; Covid-19'un yaptığı fiziksel hasarın yanında halkın ve özellikle de salgında ön cephede mücadele eden sağlık çalışanlarının ruh sağlığı üzerinde ciddi bir etkisi bulunmaktadır. İşle ilişkili stres, uzun çalışma vardiyaları, sayısız ölümün bir arada bulunması, tedavi ile ilgili belirsizlikler potansiyel birçok endişe nedenlerinden sadece birkaçı olabilir. Bu çalışma mevcut Covid-19'lu hastaların bakımında aktif olarak görev alan ve hastalıkla en çok karşılaşan grup olan sağlık çalışanlarının düşüncelerini belirlemek amacıyla yapılmıştır.

\section{Yöntem}

Covid-19'un ana merkezi Asya-Çin olarak başlayıp sonra ikincil merkez olarak Avrupa'da hızlı yayılım gösteren Covid-19 Türkiye'nin jeolojik yerleşimi, ticari açılardan da Asya ile Avrupa arasında bir köprü olması nedeni ile başlangıcından bu yana önemini kaybetmemiştir. Ülkelerin sağlık politikası, ön hazırlıkları, toplumun yaş ortalaması gibi faktörler; hastalığın seyri, salgının kontrol altına alınma süresi, yaşanabilecek ruhsal sorunların çeşitliliği ve şiddeti gibi durumlarla ilgili süreci etkilemektedir. Türkiye'deki ilk vakanın görülme tarihi Sağlı bakanlığı tarafından 10 Mart 2020 olarak belirtilmektedir (Sağlık Bakanlığı, 2020b). Araştırmada Isparta ilini tercih etme nedenimiz ülkemizde ilk haftalarda hastalığın görülme oranının nüfusa oranla en yüksek il olmasından kaynaklanmaktadır. Tanımlayıcı ve kesitsel tipte olan bu araştırmanın evrenini salgın 
sırasında ildeki ilk vakalar itibariyle hasta yatışının en çok olduğu ve bakım sürecinde aktif rol alan Isparta Şehir Hastanesindeki sağlık çalışanları oluşturmuştur. Hazırladığımız anket sağlık çalışanlarına çevrimiçi olarak gönderilmiş ve cevaplamaları istenmiştir. Covid-19'lu hastalara tedavi ve bakım veren anketi çevrimiçi olarak dolduran 407 sağlık çalışanı örneklem grubunu oluşturmuştur. Bu çalışma için ayrıca Süleyman Demirel Üniversitesi Tıp Fakültesi Klinik Araştırmalar Etik Kurulundan, 23.07.2020 tarih ve 174 nolu karar ile etik bilimsel standartlar açısından uygunluğuna karar verilmiştir.

\section{Veri Toplama Aracı}

Araştırmada kullanılan kişisel bilgi formu araştırmacılar tarafindan oluşturulmuştur. Kişisel bilgi formunda yaş, cinsiyet, eğitim durumu, meslek, aile yapısı, çocuk sahibi olma, düzenli görüşülen arkadaş gruplarının varlığı ve salgın öncesinde psikolojik destek alma ile ilgili 9 soru yer almaktadır.

Araştırmacıların Depresyon, Anksiyete ve Stres durumunu ölçmek için Henry ve Crawford (2005) tarafından oluşturulan 21 soruluk kısa form (DASS-21) kullanılmıştır. Form depresyon, stres ve anksiyete boyutlarını ölçmek için 21 maddeden ve 3 alt boyuttan oluşmaktadır. Ölçek 0 "bana hiç uygun değil" ile 3 "bana tamamen uygun" arasında puanlanan 4'lü likert tipi bir derecelendirmeye sahiptirDASS-21 kısa formun puanlaması uzun formda olduğu gibidir. Ölçek Anksiyete (DASS-21A), Depresyon (DASS-21D) ve Stres (DASS-21S) olmak üzere 3 alt boyuttan oluşmaktadır. Her alt boyut için en düşük puan 0, en yüksek puan ise 21'dir. DASS-21 ölçeğinin geçerlilik ve güvenirlik çalışması 2017 'de Yılmaz ve ark., tarafindan yapılarak Türk toplumuna uyarlanmıştır (Yılmaz vd., 2017:78-91). Anketin üçüncü bölümünde ise araştırmacılar tarafından ilgili literatür taraması ve Türkiye'deki durum göz önüne alınarak oluşturulmuş olan 30 maddelik Sağlık çalışanlarının salgın öncesi ve sonrası düşüncelerini karşılaştırmalı olarak yanıtlanabildiği sorulardan oluşmaktadır.

\section{İstatistiksel Analiz}

Veriler, SPSS 22.0 istatistik paket programında tanımlayıcı istatistikler, t-testi, Tek Yönlü Varyans Analizi, Kruskall Wallis, Wilcoxon işaret testi ile değerlendirilmiştir. 0.05 'ten küçük p değeri istatistiksel olarak anlamlı kabul edilmiştir.

\section{Bulgular}

Çalışmaya katılan sağlık çalışanlarının yaş ortalaması $38.37 \pm 7.29$ (21-54) olarak bulunmuştur. Katılımcıların \%67.6's1 kadın, \%42.0'1 hemşire, \%83.5'i üniversite mezunudur. Sağlık çalışanlarının \%72.2'si evli, \%70.0'1 çocuk sahibi, \%84.5'i çekirdek aile yapısına sahip, \%81.1'inin düzenli görüştügü arkadaş gruplarının olduğu ve \%73.5'inin Covid-19 salgınından önce psikolojik destek almadığ saptanmıştır. Sağlik çalışanlarına uygulanan DASS-21 ölçeğinden aldıkları toplam puan $27.38 \pm 16.30$, DASS-21A alt boyutundan $9.01 \pm 6.30$, DASS-21D alt boyutundan $8.68 \pm 6.23$, DASS-21S alt boyutundan $9.71 \pm 5.57$ puan aldığı belirlenmiştir. 
Tablo 1: Sağlık Çalışanlarının Demografik Özelliklerinin DASS-21 Ölçek Ve Alt Boyutlarından Aldığ 1 Puan Ortalamalarının Dağılımı

\begin{tabular}{|c|c|c|c|c|c|c|c|}
\hline \multicolumn{2}{|c|}{$\begin{array}{l}\text { Demografik } \\
\text { Özellikler }\end{array}$} & \multirow{2}{*}{$\begin{array}{l}\text { Sayı } \\
26\end{array}$} & \multirow{3}{*}{$\begin{array}{l}\% \\
6.40 \\
9.30\end{array}$} & \multirow{2}{*}{$\begin{array}{l}\text { DASS-21 } \\
\text { Ort } \pm \text { SD } \\
17.50 \pm 13.67\end{array}$} & \multirow{2}{*}{$\begin{array}{l}\text { DASS-21A } \\
\text { Ort } \pm \text { SD } \\
5.42 \pm 5.80\end{array}$} & \multirow{2}{*}{$\begin{array}{l}\text { DASS-21D } \\
\text { Ort } \pm \text { SD } \\
5.27 \pm 4.73\end{array}$} & \multirow{2}{*}{$\begin{array}{l}\text { DASS-21S } \\
\text { Ort } \pm \text { SD } \\
6.81 \pm 6.18\end{array}$} \\
\hline Yaş & $21-25$ & & & & & & \\
\hline grubu & $26-30$ & 38 & & $27.32 \pm 15.01$ & $9.34 \pm 6.04$ & $7.61 \pm 6.57$ & $10.63 \pm 5.87$ \\
\hline & $31-35$ & 57 & 14.00 & $31.42 \pm 16.81$ & $10.12 \pm 6.30$ & $10.75 \pm 6.59$ & $10.51 \pm 5.99$ \\
\hline & $35-40$ & 113 & 27.80 & $27.82 \pm 17.57$ & $9.30 \pm 6.71$ & $8.52 \pm 6.67$ & $10.00 \pm 5.60$ \\
\hline & $41-45$ & 116 & 28.50 & $28.66 \pm 15.70$ & $9.31 \pm 6.24$ & $9.27 \pm 5.84$ & $10.08 \pm 5.60$ \\
\hline & $46-50$ & 36 & 8.80 & $28.19 \pm 14.61$ & $8.56 \pm 5.72$ & $10.17 \pm 4.87$ & $9.47 \pm 5.18$ \\
\hline & $51-55$ & 21 & 5.20 & $17.95 \pm 12.54$ & $7.38 \pm 5.14$ & $4.29 \pm 4.03$ & $6.29 \pm 4.51$ \\
\hline $\mathrm{F}$ & & & & 3.628 & 2.104 & 5.094 & 3.104 \\
\hline $\mathrm{p}$ & & & & 0.000 & 0.052 & 0.000 & 0.060 \\
\hline \multirow[t]{2}{*}{ Cinsiyet } & Kadın & 275 & 67.60 & $28.34 \pm 16.64$ & $9.31 \pm 6.49$ & $9.04 \pm 6.31$ & $10.02 \pm 5.69$ \\
\hline & Erkek & 132 & 32.40 & $25.38 \pm 15.45$ & $8.39 \pm 5.86$ & $7.92 \pm 6.02$ & $9.07 \pm 5.29$ \\
\hline $\mathrm{t}$ & & & & 1.720 & 1.435 & 1.700 & 1.613 \\
\hline $\mathrm{p}$ & & & & 0.078 & 0.152 & 0.090 & 0.108 \\
\hline \multirow[t]{3}{*}{ Meslek } & Hemşire & 171 & 42.00 & $27.28 \pm 17.28$ & $9.14 \pm 6.59$ & $8.50 \pm 6.47$ & $9.70 \pm 5.66$ \\
\hline & Doktor & 125 & 30.70 & $28.18 \pm 14.35$ & $9.03 \pm 5.39$ & $9.37 \pm 5.66$ & $9.78 \pm 4.68$ \\
\hline & Diğer & 111 & 27.30 & $26.64 \pm 16.92$ & $8.78 \pm 6.79$ & $8.18 \pm 6.45$ & $9.66 \pm 6.35$ \\
\hline KW & & & & 1.751 & 0.513 & 2.862 & 0.099 \\
\hline $\mathrm{p}$ & & & & 0.417 & 0.774 & 0.239 & 0.952 \\
\hline Eğitim & Lise & 67 & 16.40 & $25.69 \pm 16.24$ & $7.70 \pm 6.78$ & $8.93 \pm 5.75$ & $9.20 \pm 5.49$ \\
\hline Durumu & Üniversite & 340 & 83.50 & $27.71 \pm 16.32$ & $9.41 \pm 6.24$ & $8.49 \pm 6.26$ & $9.84 \pm 5.57$ \\
\hline $\mathrm{t}$ & & & & -0.930 & -2.021 & 0.530 & -0.857 \\
\hline $\mathrm{p}$ & & & & 0.353 & 0.044 & 0.597 & 0.392 \\
\hline Medeni & Bekar & 113 & 27.80 & $24.05 \pm 15.44$ & $8.84 \pm 6.30$ & $6.35 \pm 5.42$ & $8.87 \pm 6.04$ \\
\hline durum & Evli & 294 & 72.20 & $28.66 \pm 16.47$ & $9.07 \pm 6.30$ & $9.58 \pm 6.29$ & $10.03 \pm 5.36$ \\
\hline $\mathrm{t}$ & & & & -2.645 & -0.336 & -5.142 & -1.897 \\
\hline $\mathrm{p}$ & & & & 0.009 & 0.737 & 0.000 & 0.050 \\
\hline \multirow{2}{*}{ Çocuk } & Var & 291 & 71.50 & $28.93 \pm 16.58$ & $9.28 \pm 6.36$ & $9.66 \pm 6.29$ & $10.04 \pm 5.38$ \\
\hline & Yok & 116 & 28.50 & $23.75 \pm 15.08$ & $8.39 \pm 6.13$ & $6.40 \pm 5.46$ & $8.95 \pm 5.95$ \\
\hline $\mathrm{t}$ & & & & 2.964 & 1.310 & 5.255 & 1.803 \\
\hline $\mathrm{p}$ & & & & 0.003 & 0.191 & 0.000 & 0.085 \\
\hline \multirow[t]{3}{*}{ Aile tipi } & $\begin{array}{l}\text { Çekirdek } \\
\text { aile }\end{array}$ & 344 & 84.5 & $27.56 \pm 16.64$ & $8.77 \pm 6.32$ & $9.26 \pm 6.33$ & $9.56 \pm 5.46$ \\
\hline & Geniş aile & 36 & 8.8 & $30.17 \pm 14.35$ & $12.36 \pm 5.45$ & $6.14 \pm 5.22$ & $11.61 \pm 5.69$ \\
\hline & Yalnız & 27 & 6.6 & $21.41 \pm 13.09$ & $7.59 \pm 5.65$ & $4.74 \pm 3.49$ & $9.07 \pm 6.55$ \\
\hline $\mathrm{KW}$ & & & & 5.162 & 13.960 & 18.365 & 5.544 \\
\hline $\mathrm{p}$ & & & & 0.076 & 0.001 & 0.000 & 0.063 \\
\hline \multirow{2}{*}{$\begin{array}{l}\text { Arkadaş } \\
\text { grubu }\end{array}$} & Var & 330 & 81.10 & $27.87 \pm 16.54$ & $9.32 \pm 6.33$ & $8.62 \pm 6.30$ & $9.96 \pm 5.69$ \\
\hline & Yok & 77 & 18.90 & $25.27 \pm 15.20$ & $7.69 \pm 6.01$ & $8.94 \pm 5.95$ & $8.65 \pm 4.94$ \\
\hline $\mathrm{t}$ & & & & 1.328 & 2.053 & -0.397 & 2.031 \\
\hline $\mathrm{p}$ & & & & 0.187 & 0.036 & 0.691 & 0.044 \\
\hline \multirow{3}{*}{$\begin{array}{l}\text { Geçmişte } \\
\text { psikoloji } \\
\text { k destek } \\
\text { t }\end{array}$} & Almış & 108 & 26.50 & $33.25 \pm 14.54$ & \multirow{2}{*}{$\begin{array}{l}10.93 \pm 6.06 \\
8.32 \pm 6.25\end{array}$} & \multirow{2}{*}{$\begin{array}{l}10.78 \pm 5.95 \\
7.92 \pm 6.16\end{array}$} & $11.64 \pm 4.64$ \\
\hline & Almamış & 299 & 73.50 & $25.26 \pm 16.41$ & & & $9.01 \pm 5.72$ \\
\hline & & & & 4.725 & 3.802 & 4.230 & 4.723 \\
\hline $\mathrm{p}$ & & & & 0.000 & 0.000 & 0.000 & 0.000 \\
\hline
\end{tabular}


Araştırmada sağlık çalışanlarının demografik verileri ile kullanılan ölçek puanlarının dağılımı tablo 1'de gösterilmiştir. Sağlık çalışanlarının yaşları gruplandırılarak değerlendirildiğinde, çalışanların çoğunluğunu 35-45 yaş arasındaki bireyler oluşturmuştur. Özellikle 31-35 yaş arası çalışanların DASS-21 skoru en yüksek bulunurken, 21-25 yaş arası ve 5155 yaş arası çalışanların DASS-21 toplam ölçek puanı ve alt boyut puanları en düşük olarak saptanmıştır. Yaş grupları arasında DASS-21 toplam ölçek puanları arasında istatistiksel olarak anlamlı farklılık bulunmaktadır $(\mathrm{F}=3.628, \mathrm{p}=0, .002)$. Aynı zamanda yaş grupları ile DASSS-21 D alt boyut puanı arasında da anlamlı fark görülmüştür $(\mathrm{F}=5, .094, \mathrm{p}=0.000)$. Cinsiyet ile DASS-21 ölçek puanları karşılaştırıldığında istatistiksel olarak anlamlı fark bulunmamıştır ( $>0.05)$. Araştırmaya katılan sağlık çalışanları hemşire, doktor ve diğer sağlık personeli olarak gruplandırılmıştır. Diğer sağlık personeli grubunu laborantlar, hasta nakil personelleri ve sekreterler oluşturmaktadır. DASS-21 ölçek puanları ile meslekler karşılaştırıldığında en yüksek puanın doktor grubunda olduğu, meslekler arasında DASS-21 puanları arasında istatistiksel anlamlıfark olmadığ 1 görülmektedir $(\mathrm{KW}=1.751 / \mathrm{p}=0.417)$. Eğitim durumu ile ölçek puanları karşılaştırıldığında ölçek toplam puanı arasında bir fark izlenmezken alt boyutlardan DASS-21A puanı ile üniversite mezunlarının puanı arasında istatistiksel olarak anlamlı farklılık bulunmuştur $(\mathrm{t}=-2.021 / \mathrm{p}=0.044)$. Çalışmaya katılan sağlık çalışanlarının medeni durumlarına bakıldı̆̆ında evli olanlarda DASS-21 toplam puanı ve alt boyut puanları bekar olanlardan daha yüksek bulunmuştur. Evli olma durumu ile DASS-21 toplam puan1, DASS-21D ve DASS-21S alt boyut puanlar1 arasında anlamlı fark olduğu belirlenmiştir $(\mathrm{t}=-2, .645 / \mathrm{p}=0.009) \quad(\mathrm{t}=-5.142 / \mathrm{p}=0.000) \quad(\mathrm{t}=-1.897$, $\mathrm{p}=0.050)$. Çocuk sahibi olanların DASS-21 toplam puanı ile DASS-21D alt boyutları arasında istatistiksel anlamlıfark olduğu bulunmuştur $(\mathrm{t}=2.964 / \mathrm{p}=0.003)(\mathrm{t}=5.255 / \mathrm{p}=0.000)$. Araştırmaya katılan sağlık çalışanlarının aile tipi ile DASS-21 karşılaştırıldığında yalnız yaşayanların en düşük ölçek puanına sahip oldukları görülmektedir. Ölçek toplamı ve alt boyutlarından alınan en yüksek puanlar geniş aile şeklinde yaşayan çalışanlar tarafindan alınmıştır. Aile tipi ile DASS-21D ve DASS-21A alt boyutları arasında anlamlı fark olduğu bulunmuştur (KW=13.960/ $\mathrm{p}=0.001)$, $(\mathrm{KW}=18.365 / \mathrm{p}=0.000)$. Katılımcıların düzenli görüştükleri bir arkadaş gruplarının olması ile DASS-21S alt boyut puanı arasında anlamlı fark olduğu görülmektedir $(\mathrm{t}=2.031 / \mathrm{p}=0.044)$. Araştırmaya katılan sağlık çalışanlarının Covid-19 salgını öncesinde psikolojik destek almış olma durumları ile ölçek toplam puan ve alt boyutları arasında istatistiksel anlamlılık bulunmaktadır $(\mathrm{p}=0.000)$ (Tablo 1).

Tablo 2: Sağlık Çalışanlarının Covid-19 Salgını Öncesi Ve Sonrası Düşüncelerinin Dağılımı

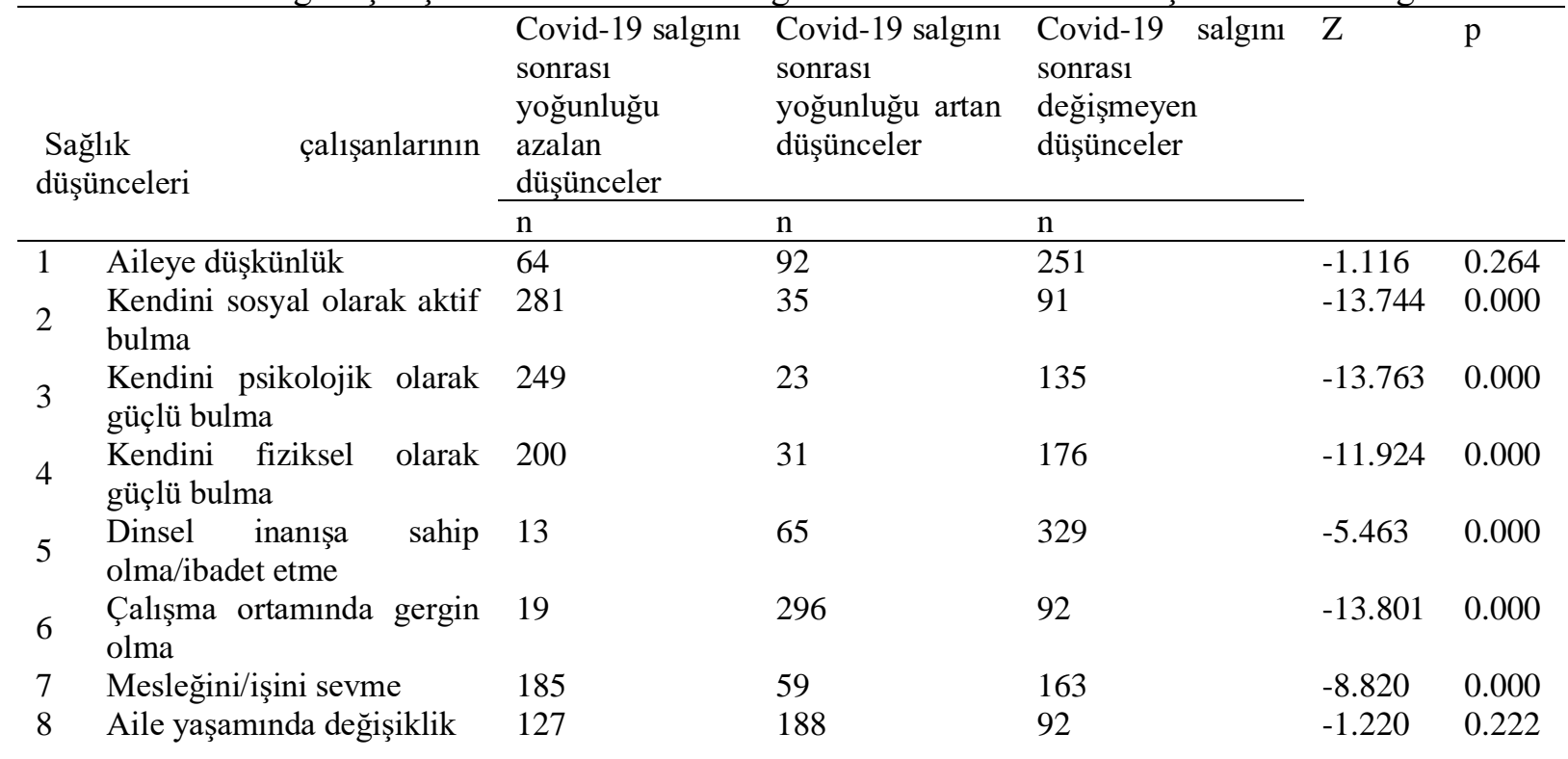

www.turkishstudies.net/turkishstudies 


\begin{tabular}{|c|c|c|c|c|c|c|}
\hline 9 & Özlem duygusu & 14 & 36 & 157 & -12.763 & 0.000 \\
\hline 10 & $\begin{array}{l}\text { İş bırakma isteği/istifa } \\
\text { düşüncesi }\end{array}$ & 34 & 200 & 173 & -10.751 & 0.000 \\
\hline 11 & Uykusuzluk yaşama & 12 & 252 & 143 & -13.583 & 0.000 \\
\hline 12 & $\begin{array}{l}\text { Sikıntıda } \\
\text { hissetme }\end{array}$ & 11 & 279 & 117 & -14.240 & 0.000 \\
\hline 13 & $\begin{array}{l}\text { Yaşamın } \\
\text { hissetme }\end{array} \quad$ ağırlığını & 13 & 238 & 156 & -13.313 & 0.000 \\
\hline 14 & Herşeyden kaçma isteği & 2 & 276 & 129 & -14.584 & 0.000 \\
\hline 15 & İntihar düşüncesi yaşama & 2 & 117 & 288 & -9.566 & 0.000 \\
\hline 16 & $\begin{array}{l}\text { Kendileri ile ilgili Ölüm } \\
\text { kaygısı yaşama }\end{array}$ & 2 & 234 & 171 & -13.518 & 0.000 \\
\hline 17 & $\begin{array}{l}\text { Sevdikleri ilgili Ölüm } \\
\text { kaygısı yaşama }\end{array}$ & 2 & 270 & 135 & -14.479 & 0.000 \\
\hline 18 & Hastalara karşı öfke duyma & 9 & 220 & 178 & -12.758 & 0.000 \\
\hline 19 & $\begin{array}{l}\text { Sağlık sistemine karşı öfke } \\
\text { duyma }\end{array}$ & 8 & 185 & 214 & -11.884 & 0.000 \\
\hline 20 & İşi bırakma isteği & 4 & 205 & 198 & -12.573 & 0.000 \\
\hline & Kriz anında & 0 & 175 & 232 & -11.794 & 0.000 \\
\hline 21 & $\begin{array}{l}\text { bırakamayacağı için kızgın } \\
\text { hissetme }\end{array}$ & & & & & \\
\hline 22 & $\begin{array}{ll}\text { İşe gelememe durumunda } \\
\text { iş arkadaşlarının çalışma } \\
\text { yükü artarsa } & \text { kendini } \\
\text { suçlama } & \end{array}$ & 13 & 199 & 195 & -10.971 & 0.000 \\
\hline 23 & $\begin{array}{l}\text { Temel ihtiyaçların yeterli } \\
\text { karşılandığını düşünme }\end{array}$ & 96 & 111 & 200 & -0.806 & 0.421 \\
\hline 24 & $\begin{array}{l}\text { Çalışırken sosyal destek } \\
\text { görme }\end{array}$ & 29 & 74 & 304 & -3.303 & 0.000 \\
\hline 25 & $\begin{array}{l}\text { Çalışırken damgalanma } \\
\text { yaşadığını düşünme }\end{array}$ & 7 & 165 & 235 & -11.242 & 0.000 \\
\hline 26 & $\begin{array}{l}\text { İzolasyonlar nedeni ile } \\
\text { çaresizlik hissetme }\end{array}$ & 11 & 257 & 139 & -13.754 & 0.000 \\
\hline 27 & $\begin{array}{l}\text { Kriz yönetiminin } \\
\text { yönetildiğini düşünme }\end{array}$ & 54 & 133 & 220 & -4.317 & 0.000 \\
\hline 28 & $\begin{array}{l}\text { Çalışma saatlerinde yapılan } \\
\text { ani değişiklikleri } \\
\text { kabullenebilme }\end{array}$ & 83 & 172 & 152 & -6.468 & 0.000 \\
\hline 29 & $\begin{array}{l}\text { kabullenebilme } \\
\text { İdareciler tarafindan } \\
\text { desteklendiğini düşünme }\end{array}$ & 19 & 115 & 273 & -8.542 & 0.000 \\
\hline 30 & $\begin{array}{l}\text { Çalışma süresi ve } \\
\text { sonrasında öz bakımınızda } \\
\text { özen gösterme }\end{array}$ & 86 & 132 & 189 & -0.584 & 0.559 \\
\hline
\end{tabular}

Araştırmaya katılan sağlık çalışanlarına Covid-19 salgını öncesi ve sonrasında bazı duyguları yaşama ve bazı davranışları devam ettirme durumları hakkında görüşleri alınmıştır. Sağlık çalışanlarının bu sorulara verdikleri cevaplar tablo 2'de gösterilmiştir. Sorulardan aileye düşkün olma $(\mathrm{p}=0.264)$, aile yaşamında değişiklik yaşama $(\mathrm{p}=0.222)$, temel ihtiyaçların yeterli karşılandığ 1 düşüncesi $(\mathrm{p}=0.421)$ ve çalışma sırası ve sonrasında öz bakıma özen gösterme düzeyleri $(\mathrm{p}=0.559)$ ile ilgili durumlarına verilen yanıtlar istatistiksel anlamlılık göstermemiştir (Tablo 2). Katılımcıların bazıları Covid-19 salgını öncesi kendilerini sosyal olarak aktif buldukları $(n=281)$, fiziksel $(n=249)$ ve psikolojik $(n=200)$ yönlerden daha güçlü hissettikleri mesleklerini daha çok severek yaptıkları $(\mathrm{n}=185)$ ancak bu durumun Covid-19'dan sonra olumsuz olarak etkilendiğini belirtmişlerdir (Tablo 2). 
Özellikle bazı sorular için covid-19 salgını öncesi ve sonrasında yaşanılan duygularla ilgili verilen yanıtlardaki artış dikkat çekici boyutlardadır. Katılımcıların çoğu salgın çalışma ortamında gergin olduğunu, istifa etmeyi düşündüğünü ve bu dönemde istifa haklarının kaldırılması nedeni ile kızgınlık yaşadıklarını, sağlık sistemine ve hastalara karşı öfke duyduklarını, herhangi bir nedenle işe gelemediklerinde arkadaşlarının artan iş yükünden kendilerini sorumlu tuttuklarını, damgalanma yaşadıklarını düşündüklerini, uyku sorunu yaşadıklarını, yaşamın ağırlığının arttığını ve kendilerini çıkmazda hissettiklerini, kendileri ve sevdikleri ile ilgili ölüm kaygısı yaşadıklarını, izolasyonlar nedeni ile daha çok çaresiz hissettiklerini, idarecileri tarafından bu dönemde daha çok desteklendiklerini ifade etmişlerdir.

\section{Tartışma}

Koronavirüs salgınının yaklaşık 5 ay içinde 170 'den fazla ülkeyi etkilemesi ile birlikte, ülkelerde fiziksel iyilik halinin devam etmesi için birçok öneri yayınlanmıştır. Bunun yanı sıra bu kadar aktif bir hastalığı iyi yönetebilmek için çaba gösteren sağlık çalışanlarının ruhsal ve mental yönden de iyilik hallerinin sürdürülmesi gerekmektedir. Ülkelerdeki sağlık kurulları bu konu ile alakalı olarak ta birçok öneride bulunmaktadır. Covid-19 salgını ile ilgili ilk yapılan yayınlarda da bu önerileri sıkça bulabilmekteyiz (Petzold vd., 2020:417-421; Holmes vd., 2020:30168-30171; https://www.psikiyatri.org.tr/menu/161/cov\%C4\%B1d-19-ve-ruh-sagligi, 2020). Ancak bu önerilerin büyük çoğunluğu daha önceki yaşanan hastalıklar ya da olağan dışı durumlarda verilen tepkiler göz önüne alınarak yapılmaktadır. Covid-19 salgın süreci ile ilgili yeterli veri bulunmamasının bir eksiklik olduğu düşüncesinden yola çıkarak; çalışmada özellikle sağlik çalışanlarının Covid19 salgınının erken dönemindeki ruhsal ve psikolojik duygu durumlarını ve düşüncelerini belirleyerek sürecin etkin yönetimine katkı sağlaması hedeflenmiştir.

SARS salgını sırasında yapılan bir çalışmada, yüksek riskli durumlardaki sağlık çalışanlarının \% 89.0'ında psikolojik sorunların gözlendiği belirtilmiştir (Chua vd., 2004:391-393). $\mathrm{Bu}$ çalışmada ise DASS-21 ölçeğinden alınan puanların çok yüksek olmaması örneklem grubumuzdaki sağlık çalışanlarının Covid-19 salgın durumuna hızlı adapte olduklarını düşündürmektedir. Ancak düşüncelerini değerlendirdiğimiz sorulara verilen yanıtları incelediğimizde erken dönemde işlerini daha az severek yaptıkları, daha fazla istifayı düşündükleri ve istifa edemeyecekleri için kendilerini kızgın hissettikleri, kendileri ve yakınları ile ilgili ölüm kaygısı taşıdıkları ve paralelinde yaşam koşullarının daha ağır geldiği hatta intiharı düşündükleri yönünde verdikleri yanttlar dikkat çekicidir. Her ne kadar DASS-21 ölçek değerlendirmesinde daha 1lımlı görünseler de aslında düşünce düzeyinde ciddi kargaşalar yaşadıklarını ifade edebiliriz.

Covid-19 ile ilgili olarak Lai ve diğerlerinin (2020) yaptıkları çalışmalarında kadın cinsiyet ve düşük eğitim düzeyi anksiyete, stres ve depresyon oranlan ile ilişkilendirilmiştir. Çalışmada kadın cinsiyete sahip olanlarda DASS-21 toplam puan ve tüm alt ölçek puanları daha yüksek olmakla birlikte anlamlı fark bulunmamıştır. Lai ve diğerlerinin çalışmasının aksine bu çalışmada eğitim durumu daha yüksek olan sağlık çalışanlarının DASS-21 ile ilgili tüm puanları daha yüksek bulunmuştur. Ancak bu farkl1lıklardan sadece DASS-21A puanı istatistiksel anlamlılık göstermiştir. $\mathrm{Bu}$ bulgunun nedeni olarak eğitim düzeyi yüksek olan çalışanların salgının ciddiyetinin farkında olmalarından, daha fazla kaynaktan araştırma yapabilmeleri ayrıca bulaş riskinin yüksek olması ve durumu iyi yönetebilme konusunda yaşadıkları kaygılarından kaynaklanıyor olabileceğini düşünmekteyiz.

Meslekler açısından değerlendirildiğinde doktorların DASS-21 total puanlarını diğer tüm sağlık çalışanlarından daha yüksek olduğu saptanmıştır. Lai ve ark. (2020) çalışmasında ise özellikle ön cephede tedavi alanında çalışmak ve hemşire olmak ile stres, anksiyete depresyon durumlarının daha fazla yaşanabileceğinden bahsetmiştir. Daha önceki salgınlarda özellikle SARS ile ilgili çalışmalarda da hekimler ile kıyaslandığında hemşirelerde daha fazla fiziksel ve psikolojik zorlanma yaşandığı, kaçınma, yeniden yaşama durumlarının daha fazla izlendiği ve uyku bozukluklarının geliştiği belirlenmiştir (Wong vd., 2005:13-18; Shih vd., 2007:171-180; Chan, 
2003; Tzeng ve Fighting, 2003:565-567). Çalışmanın sonuçlarında puanların birbirine yakın çıkmasının nedenini bu zorlu süreçte klinikte çalışma sırasında sağlık ekibinin tüm üyelerinin birbirleri ile uyum içinde ve birbirlerini destekleyerek çalışmalarından kaynaklanmış olabileceğini düşünmekteyiz.

Evli olan sağlık çalışanlarında DASS-21 toplam puanı ve DASS-21D, DASS-21S alt boyutları istatistiksel olarak anlamlı fark gösterirken DASS-21A boyutunda da evli grubun puanları daha yüksek bulunmuştur. Ayrıca çocuk sahibi olanların benzer şekilde ölçek puanları yüksek olarak değerlendirilmiştir. Bu durumun nedeninin sağlık çalışanlarının, hastalı̆̆ bakım verdikleri ortamdan yaşadıkları ortama taşıma endişesinden köken aldığı düşünülmüştür. Özellikle aile tipi sorusunda yalnız yaşayan bireylerdeki anksiyete, depresyon ve stres düzeylerinin çok daha düşük olması bu düşüncemizi destekleyen bir diğer bulgumuzdur. Ülkemizin kültürel yapısı göz önüne alındığında sıklıkla görüşülen arkadaşlar aileden sayıldıkları için onların sağlıkları ile ilgili de kayg1 yaşadıklarından DASS-21A ve DASS-21S alt boyut puanları yüksek bulunmuştur. Daha önce yapılan çalışmalarda yaşanan durumun belirsizliği nedeni ile güvensizlik duygularının arttı̆̆ı; zihnin bunu kompanse edebilmek için; özellikle sağlıklı kalabilmek ve aile ilişkilerine daha fazla önem vermeye zorladığı ifade edilmiştir (Foulds, 1963).

Çoğunluğu SARS ile ilgili olan daha önce yapılan çalışmalarda da özellikle kriz ve enfeksiyon hastalıkları konusunda yeterli bilgiye sahip olmak, ölüm ve hastalıkları kabullenebilmek, kritik alanlarda çalışmış olmak gibi durumların, olayların ruhsal ve zihinsel etkilerini azalttığı yönünde sonuçlar saptanmıştır (Adams vd., 2008:238-250; Maunder vd., 2006:1924-1932; Wong vd., 2007:50-55; Chua vd., 2004:391-393; Linley ve Joseph, 2006:229245). Bu çalışmada özellikle Covid-19 salgınının başlangıç döneminde hastalıkla ilgili yeterli bilgi ve verinin olmamasından dolayı yaşanan ölüm kaygıları ile sağlık çalışanları daha gergin, işine olan sevgi ve ilgisini kaybetme gibi ciddi kaygılar yaşamışlardır. Katılımcılar Covid-19 sonrasında aileye karşı bağlılıklarının ve endişelerinin arttığı, dinsel inanışa sahip olma/ibadet etme düzeyinde artış olduğu, mesleki açıdan işini sevme, kurum aidiyeti gibi düşüncelerin zayıfladığı, uykusuzluk, gerginlik, stresle baş etmede zorlanma, çaresizlik duygusunun ve intihar düşüncesi yaşama düşüncelerinin arttığı bulunmuştur. Liv ve arkadaşlarının (2020) çalışmalarında makine öğrenme modelleri üzerinden halkın salgını öğrendikten sonraki psikolojik durumlarını değerlendirmiş ve genel olarak yoğun endişe, depresyon, öfke, gibi olumsuz duyguların artmakta olduğunu ifade etmişlerdir. Ayrıca bireylerin yaşam doyumlarının azaldığı ve sağlıkları ile ilgili kaygı düzeylerinin arttığ 1 ifade edilmektedir. Bu çalışmaya katılan grup aktif olarak Covid-19 hastalarına tedavi ve bakımda görev aldıkları için bu tür duyguları daha yoğun yaşaması muhtemeldir. Yaşanan kriz dönemlerinden sonraki ruhsal sağlığın sosyal destekle yakın ilişkili olduğu birçok çalışmada vurgulanmış ve bu konuda yapılması gerekenlerden bahsedilmiştir (Brooks vd., 2016:18; Brooks vd., 2019:25-34; Greenberg vd., 2020:m1211).

\section{Sonuç}

Bu çalışmada sağlık çalışanlarının çoğunluğunun erken dönemde bile salgına ve vakalara karşı beklenen düzeyde olumsuz bir tutum içinde olmadıkları bulunmuştur. Ayrıca çalışmada sağlık çalışanları anksiyete depresyon ve stres bozukluklarını daha az yaşadıkları ve salgından daha az olumsuz etkilendikleri bulunmuştur. Bu düşünceleri yaşarken aynı zamanda birçok içsel kargaşa yaşadıklarını da ifade etmişlerdir. Toplumumuzun kültürel yapısı gereği sağlık çalışanlarımıza toplumsal olarak gösterilen saygı sevgiden dolayı ayrıca çalışma ülkemizde ilk vakaların görüldüğü haftalarda planlanmasından dolayı sağlık çalışanlarımızda yoğun stres, anksiyete ve depresyon belirtileri görülmemiştir. Covid-19 salgını sonrasında ki dönemde daha büyük sorunlar yaşamamak için sağlık çalışanlarının tamamına yönelik psikolojik destek programları düzenlenmelidir. 


\section{Kaynakça}

Adams, R.E. , Figley, C.R. , Boscarino, J.A. (2008). The compassion fatigue scale: Its use with social workers following urban disaster. Res Soc Work Pract, 18, 238-250. https://doi.org/10.1177/1049731507310190

Ağalar, C., Öztürk Engin, D. (2020). Protective measures for COVID-19 for healthcare providers and laboratory personnel. Turk J Med Sci, 50(SI-1),578-584. https://doi.org/10.3906/sag2004-132

Brooks, S., Amlôt, R., Rubin, G.J., Greenberg, N. (2020). Psychological resilience and posttraumatic growth in disaster-exposed organisations: Overview of the literature. BMJ Mil Health, 166,52-56. https://doi.org/10.1136/jramc-2017-000876

Brooks, S.K., Dunn, R., Amlôt, R., et al. (2016). Social and occupational factors associated with psychological distress and disorder among disaster responders: A systematic review. BMC Psychol,4:18. https://doi.org/10.1186/s40359-016-0120-9

Brooks, S.K., Rubin, G.J., Greenberg, N. (2019). Traumatic stress within disaster-exposed occupations: Overview of the literature and suggestions for the management of traumatic stress in the workplace. Br Med Bull, 129(1),25-34. https://doi.org/10.1093/bmb/ldy040

Brown, T.A., Chorpita, B.F., Korotitsch, W., Barlow, D.H. (1997). Psychometric properties of The Depression Anxiety Stress Scales (DASS) in clinical samples. Behav Res Ther, 35(1),7989. https://doi.org/10.1016/s0005-7967(96)00068-x

Chan, S. (2003). Nurses fighting against Severe Acute Respiratory Syndrome (SARS) in Hong $\begin{array}{lllll}\text { Kong. J } & \text { Nurs }\end{array}$ https://doi.org/10.1111/j.1547-5069.2003.00209.x

Chua, S.E., Cheung, V., Cheung, C., et al. (2004) . Psychological effects of the SARS outbreak in Hong Kong on high-risk health care workers. Can J Psychiatry, 49(6),391-393. https://doi.org/10.1177/070674370404900609

COVID-19 Case Tracker (2020). Johns Hopkins University and Medicine Coronavirus Resource Center. https://coronavirus.jhu.edu/. (Erişim tarihi: 16.04.2020).

Foulds, G.A. (1963). A Theory of cognitive dissonance. Br. J. Psychiatry, 109,164-165.

Greenberg, N., Docherty, M., Gnanapragasam, S., Wessely, S. (2020). Managing mental health challenges faced by healthcare workers during Covid-19 pandemic. BMJ, 368:m1211. https://doi.org/10.1136/bmj.m1211

Henry, J.D., Crawford, J.R. (2005). The short- form version of The Depression Anxiety Stress Scales (DASS- 21): Construct validity and normative data in a large non- clinical sample. Br J Clin Psychol,44(2),227-239. https://doi.org/10.1348/014466505x29657

Holmes, E.A., O'Connor, R.C., Perry, V.H., et al. (2020). Multidisciplinary research priorities for the COVID-19 Pandemic: a call for action for mental health science. Lancet Psychiatry, 0366(20), 30168-1.

Lai, J., Ma, S., Wang, Y., et al. (2020). Factors associated with mental health outcomes among health care workers exposed to Coronavirus disease 2019. JAMA Netw Open,3(3), e203976. https://doi.org/10.1001/jamanetworkopen.2020.3976

Li, S., Wang, Y., Xue, J., Zhao, N., Zhu, T. (2020). The impact of COVID-19 epidemic declaration on psychological consequences: A study on active weibo users. Int. J Environ Res Public Health, 17(6),2032. https://doi.org/10.3390/ijerph17062032 
Linley, P.A., Joseph, S. (2006). The positive and negative effects of disaster work: A preliminary investigation. $\mathrm{J}$ Loss and Trauma. 11(3), 229-245. https://doi.org/10.1080/15325020500494186

Lovibond, P.F., Lovibond, S.H. (1995). The structure of negative emotional states: comparison of the Depression Anxiety Stress Scales (DASS) with the beck depression and anxiety inventories. Behav Res Ther, 33(3), 335-343. https://doi.org/10.1016/0005-7967(94)00075$\mathrm{u}$

Mak, I.W., Chu, C.M., Pan, P.C., Yiu, M.G., Chan, V.L. (2009) Long-term psychiatric morbidities among SARS survivors. Gen Hosp Psychiatry,31(4),318-26. https://doi.org/10.1016/j.genhosppsych.2009.03.001

Maunder, R.G., Lancee, W.J., Balderson, K.E., et al. (2006). Long-term psychological and occupational effects of providing hospital healthcare during SARS outbreak. Emerg Infect Dis, 12:1924-32. https://doi.org/10.3201/eid1212.060584

Petzold, M.B., Plag, J., Ströhle, A. (2020) Umgang mit psychischer belastung bei gesundheitsfachkräften im rahmen der Covid-19-Pandemie [Dealing with psychological distress by healthcare professionals during the COVID-19 pandemia]. Nervenarzt, 91(5),417-421. https://doi.org/10.1007/s00115-020-00905-0

Rohan, P., O'Reilly, M.K., Gibney, B., Nason, G.J. (2020) supply of personal protective equipment (PPE) during the Covid-19 pandemic. Ir Med J, 113(4),66.

Shih, F.J., Gau, M.L., Kao, C.C., et al. (2007) . Dying and caring on the edge: Taiwan's surviving nurses' reflections on taking care of patients with Severe Acute Respiratory Syndrome. Appl Nurs Res,20(4),171-180. https://doi.org/10.1016/j.apnr.2006.08.007

Shultz, J.M., Cooper, J.L., Baingana, F., et al. (2016). The role of fear-related behaviors in the 2013-2016 West Africa Ebola virus disease outbreak. Curr Psychiatry Rep, 18(11),104. https://doi.org/10.1007/s11920-016-0741-y

The Lancet. (2020). COVID-19: Protecting health-care workers. Lancet,395(10228),922. https://doi.org/10.1016/s0140-6736(20)30644-9

Türkiye Cumhuriyeti Sağlık Bakanlığı (2020a). https://covid19bilgi.saglik.gov.tr/tr/, (Erişim tarihi: 06.05.2020)

Türkiye Cumhuriyeti Sağlık Bakanlığı (2020b). Halk sağlığ1 genel müdürlüğü. https://covid19bilgi.saglik.gov.tr/depo/Sunumlar/COVID-19-Epidemiyoloji-Tani-

Tedavi.pdf. (Erişim tarihi: 06.05.2020).

Türkiye Psikiyatri Derneği Ruhsal Travma ve Afet Psikiyatrisi Çalışma Birimi. https://www.psikiyatri.org.tr/menu/161/cov\%C4\%B1d-19-ve-ruh-sagligi. (Erişim tarihi:06.05.2020). https://doi.org/10.1501/kriz_0000000298

Tzeng, H.M. (2003). Fighting The SARS epidemic in Taiwan: A nursing perspective. J Nurs Adm,33(11),565-567. https://doi.org/10.1097/00005110-200311000-00005

Wong, T.W., Yau, J.K., Chan, C.L., et al. (2005). The psychological impact of severe acute respiratory syndrome outbreak on healthcare workers in emergency departments and how they cope. Eur J Emerg Med,12(1),13-18. https://doi.org/10.1097/00063110-20050200000005

Wong, W.C., Wong, S.Y., Lee, A., et al. (2007). How to provide an effective primary health care in fighting against Severe Acute Respiratory Syndrome: The experiences of two cities. Am J Infect Control, 35,50-55. https://doi.org/10.1016/j.ajic.2006.06.009 
World Health Organization Statement on the second meeting of the International Health Regulations. (2020). Emergency Committee regarding the outbreak of novel coronavirus (2019-nCoV). https://www.who.int/news-room/detail/30-01-2020-statement-on-thesecond-meeting-of-the-international-health-regulations-(2005)-emergency-committeeregarding-the-outbreak-of-novel-coronavirus-(2019-ncov). (Erişim tarihi: 16.04.2020).

Wu, P., Fang, Y., Guan, Z., et al. (2009). The psychological impact of the SARS epidemic on hospital employees in China: Exposure, risk perception, and altruistic acceptance of risk. Can J Psychiatry,54(5),302-311. https://doi.org/10.1177/070674370905400504

Xiang, Y.T., Yang, Y., Li, W., et al. (2020). Timely mental health care for the 2019 novel Coronavirus outbreak is urgently needed. Lancet Psyc,7(3),228-229. https://doi.org/10.1016/s2215-0366(20)30046-8

Yılmaz, Ö., Boz, H., Arslan, A. (2017). Depresyon Anksiyete Stres Ölçeğinin (DASS 21) Türkçe kısa formunun geçerlilik-güvenilirlik çalışması. FESA,2(2),78-91.

Zhou, P., Yang, X.L., Wang, X.G., et al. (2020). Pneumonia outbreak associated with a new Coronavirus of probable bat origin. Nature, 579(7798), 270-273. 